Article

\title{
Green Procedure for Aerobic Oxidation of Benzylic Alcohols with Palladium Supported on Iota-Carrageenan in Ethanol
}

\author{
Eliraz Stamker, Oshrat Levy-Ontman $*,+\mathbb{D}$ and Adi Wolfson *,+ \\ Department of Chemical Engineering, Sami Shamoon College of Engineering, Basel/Bialik Sts., \\ Beer-Sheva 8410001, Israel; elirast@sce.ac.il \\ * Correspondence: oshrale@sce.ac.il (O.L.-O.); adiw@sce.ac.il (A.W.); Tel.: +972-8-6475636 (O.L.-O.) \\ + These authors contributed equally.
}

check for updates

Citation: Stamker, E.; Levy-Ontman, O.; Wolfson, A. Green Procedure for Aerobic Oxidation of Benzylic Alcohols with Palladium Supported on Iota-Carrageenan in Ethanol. Polymers 2021, 13, 498. https:// doi.org/10.3390/polym13040498

Academic Editor: Antonio Zuorro

Received: 5 January 2021

Accepted: 2 February 2021

Published: 5 February 202

Publisher's Note: MDPI stays neutral with regard to jurisdictional claims in published maps and institutional affiliations.

Copyright: (c) 2021 by the authors. Licensee MDPI, Basel, Switzerland. This article is an open access article distributed under the terms and conditions of the Creative Commons Attribution (CC BY) license (https:// creativecommons.org/licenses/by/ $4.0 /)$.

\begin{abstract}
The search for selective heterogeneous catalysts for the aerobic oxidation of alcohols to ketones and aldehydes has drawn much attention in the last decade. To that end, different palladium-based catalysts have been proposed that use various organic and inorganic supports. In addition, supports that originate from a biological and renewable source that is also nontoxic and biodegradable were found to be superior. We heterogenized palladium chloride or acetate complexes with triphenylphosphine trisulfonate on iota-carrageenan xerogel by simple mixing of the complex and the polysaccharide in water. The resulting polysaccharide-catalyst mixture then underwent deep freeze and lyophilization, after which the catalyst was characterized by TEM, XPS and SEMEDS and tested in aerobic oxidation. The new heterogeneous catalysts were successfully used for the first time in the aerobic oxidation of benzylic alcohols. Moreover, they were easily removed from the reaction mixture and recycled, yielding an increase in activity with each subsequent reuse. As determined by TEM and XPS, the reduction in palladium and the formation of nanoparticles during the reaction in ethanol yielded more active species and, therefore, higher conversion rates. A SEM-EDS analysis indicated that the palladium was thoroughly dispersed in the xerogel catalysts. Moreover, the xerogel catalyst was observed to undergo a structural change during the reaction. To conclude, the new heterogeneous catalyst was prepared by a simple and straightforward method that used a non-toxic, renewable and biodegradable support to yield an active, selective and recyclable heterogeneous system.
\end{abstract}

Keywords: catalysis; carrageenan; heterogeneous catalysts; oxidation

\section{Introduction}

The selective oxidation of alcohols to ketones and aldehydes, which has been attracting significant attention both in laboratory scale studies of catalysis and in industrial production, is considered a pivotal reaction in organic synthesis [1-4]. However, the scaledup application of oxidation reactions in synthesis has been severely limited by the large amounts of hazardous metal oxidants required, such as manganese or chromium oxides, which also necessitate the use of toxic solvents such as DMF and DMSO and produce excessive amounts of effluents [5]. Furthermore, running oxidation with these strong oxidants tends to result in over-oxidized products, e.g., primary alcohols are oxidized to their corresponding carboxylic acids.

To avoid the use of metal oxidants and toxic organic solvents, a cleaner and safer oxidation method was developed that uses hydrogen peroxide in water. That method, however, is limited by the low solubility of many organic compounds in water and the fact that water can react with other functional groups on the molecule [6,7]. An alternative is to use aerobic oxidation in the presence of a transition metal-based catalyst. Such a method utilizes low-cost and readily available oxygen as the oxidant while producing only water as a by-product. As such, it constitutes a "green route" for alcohol oxidation that can be performed in variety of organic solvents [8,9]. 
Over the years, many homogeneous catalysts have been suggested for this purpose, among them systems with copper [10] and iron [11] or transition-metal complexes [12,13] based mainly on palladium or ruthenium $[14,15]$. Yet if the intention is to develop an environmentally friendly, simple and inexpensive industrial protocol, homogeneous systems suffer a huge drawback: separation of the metal from the reaction mixture at the end of the reaction is a complicated process in such systems, and the catalyst cannot be recycled. In heterogeneous systems, in contrast, where the metal is immobilized on a support, the end-products are easy to separate and recycle. These benefits notwithstanding, the preparation of any heterogeneous catalyst must be as simple and as reproducible as possible, while avoiding any leaching of the metal $[16,17]$.

A variety of supported metals have been offered as heterogeneous catalysts for the oxidation of alcohols [18,19] by using different supports, for example, Pd/Alumina [20], $\mathrm{Ni} /$ Hydrotalcite [21], $\mathrm{Ru} / \mathrm{Hydroxyapatite} \mathrm{[22],} \mathrm{Co} /$ Activated carbon [23], and $\mathrm{Au} /$ Polystyrene [24]. Palladium catalysts, which have found widespread application in organic synthesis, were also extensively used to this end, and they employed different supports, such as silica [25], graphene [26], aluminum hydroxide [27], MnCeOx [28], and poly(ethyleneglycole) [29]. Additionally, the most active species in many systems were palladium nanoparticles [29-33].

Since many organic and inorganic supports can potentially be used, supports that originate from a biological and renewable source that is also nontoxic and biodegradable are superior. To that end, polysaccharides, which constitute the most prevalent form of the biopolymers and the most abundant organic material on earth, have recently been used to immobilize different metal catalysts as complexes or nanoparticles. Of note are the palladium-based catalysts, which have been used mainly in the Suzuki cross-coupling reaction [34,35] but also in other coupling reactions [36], in amination and in hydrogenation [37]. However, polysaccharides-based palladium catalysts for the aerobic oxidation of alcohols have not been proposed. Recently, we also proposed a simple and straightforward procedure to immobilize palladium complexes on various renewable polysaccharides by using sodium triphenylphosphine trisulfonate (TPPTS) as ligand and anchor. The new heterogeneous catalysts were successfully used in Suzuki cross-coupling [38-42] and Heck coupling and in the transfer hydrogenation of olefins $[43,44]$.

In this study, we report for the first time on the use of a palladium catalyst immobilized on a renewable polysaccharide in the aerobic oxidation of benzylic alcohols (Figure 1).<smiles>[Y]c1cccc(C([X])([1H])O)c1</smiles><smiles>O=[W]OC(=O)O[Mg]</smiles><smiles>[X]C(=O)c1ccccc1</smiles>

$$
\begin{aligned}
& \mathrm{X}=\mathrm{H}, \mathrm{CH}_{3} \\
& \mathrm{Y}=\mathrm{H}, \mathrm{CH}_{3}, \mathrm{OCH}_{3}
\end{aligned}
$$

Figure 1. Aerobic oxidation of benzylic alcohols.

\section{Materials and Methods}

\subsection{Polysaccharides and Reagents}

The polysaccharides, palladium acetate, palladium chloride, TPPTS, benzyl alcohol and sodium carbonate (analytical grades) were purchased from Sigma-Aldrich, Rehovot, Israel. 


\subsection{Catalyst Preparation}

In a typical procedure, $10 \mu \mathrm{mol}$ of palladium salt was added to a vial with $3 \mathrm{~mL}$ distilled water together with $30 \mu \mathrm{mol}$ of TPPTS and mixed at room temperature for $5 \mathrm{~min}$. The mixture was added to a $15-\mathrm{mL}$ polypropylene tube together with $3 \mathrm{~mL}$ of $1 \% \mathrm{wt} / \mathrm{vol}$ polysaccharide solution in distilled water, sealed and vortexed for homogenization. The tube was then placed in a deep freeze unit at $-20^{\circ} \mathrm{C}$ for $24 \mathrm{~h}$ until the liquid was completely frozen. Then the seal was removed from the tube and it was covered with a paraffin sheet that was pierced with disposable toothpick. The tube was placed in a lyophilizer (Christ, Osterode, Germany) for $48 \mathrm{~h}$. At the end of the process, the dried xerogel was cut into pieces measuring $\sim 1 \mathrm{~cm} \times 1 \mathrm{~cm}$ and added to the reaction mixture.

\subsection{Reaction Procedure}

In a typical procedure, $10 \mu \mathrm{mol}$ of palladium catalyst (homogenous or heterogeneous) was added to a vial with $5 \mathrm{~mL}$ ethanol together with $0.925 \mathrm{mmol}$ benzyl alcohol ( $\mathrm{S} / \mathrm{C}=92.5)$, with or without $0.092 \mu \mathrm{mol}$ sodium carbonate. The mixture was placed in an oil bath preheated to $60^{\circ} \mathrm{C}$ and magnetically stirred for $24 \mathrm{~h}$. At the end of the reaction, the reaction mixture was cooled, and after reactions in which a heterogeneous catalyst was used, it was removed by filtration through a $0.45 \mu \mathrm{m}$ Millex LH filter (Millipore, Bedford, MA, USA). The organic phase was then analyzed to determine conversion by GC by using an ZB-5 column (Phenomenex, Torrance, CA, USA). High-pressure reactions were tested in a homemade $10 \mathrm{~mL}$ stainless steel reactor with magnetic stirring following the same procedure.

Catalyst leaching was tested as follows: (1) testing the reaction performance of the catalyst that was removed from the original reaction mixture in a second reaction with a fresh reaction mixture that contains the initial amounts of fresh substrates and sodium carbonate used in the first reaction; (2) testing the reaction performances after catalyst removal by running the reaction mixture under similar conditions for an additional $24 \mathrm{~h}$ to test whether the conversion increases with time, and (3) performing spectro arcos ICP-OES (Agilent, Santa Clara, CA, USA) analysis of the reaction medium after the first cycle (24 h), to test for leftover palladium in the reaction solution.

Catalyst recycling was tested by adding the recovered catalyst to a solution with similar amounts of fresh substrates and base and running the reaction mixture under similar reaction conditions for an additional $24 \mathrm{~h}$.

\subsection{TEM Analysis}

HRTEM micrographs were obtained on a EFI Talos F200C electron microscope (Thermo Fischer Scientific, Gloucester, UK) operated at $200 \mathrm{kV}$ at room temperature. The samples were prepared by deposition of a drop of ethanol suspension of the solid catalyst on a carbon-coated $\mathrm{Cu}$ grid and examined as grain mounts.

\subsection{Surface Analysis by X-ray Photoelectron Spectroscopy (XPS)}

XPS data were collected by using an X-ray photoelectron spectrometer ESCALAB 250 (Thermo Fischer Scientific, Gloucester, UK) ultrahigh vacuum $\left(1 \times 10^{-9}\right.$ bar) apparatus with an $\mathrm{AlK}^{\alpha} \mathrm{X}$-ray source and a monochromator. The X-ray beam size was $500 \mu \mathrm{m}$, and survey spectra were recorded with a pass energy (PE) of $150 \mathrm{eV}$, and high energy resolution spectra were recorded with a pass energy (PE) of $20 \mathrm{eV}$. To correct for charging effects, all spectra were calibrated relative to a carbon C 1 s peak positioned at $284.8 \mathrm{eV}$. Processing of the XPS results was carried out by using AVANTAGE program (Thermo Fischer Scientific, Gloucester, UK).

\subsection{Scanning Electron Microscope (SEM) Energy Dispersive X-ray Spectrometry (EDS)}

Elemental analysis was performed by using a scanning electron microscope (SEM), FEI Verios 460L XHR (extreme high resolution, Hillsboro, OR, USA), equipped with energydispersive X-ray spectroscopy (Thermo Fischer Scientific, Gloucester, UK). 


\subsection{Analysis of Total Sugar Concentration}

At the end of the reaction, the catalyst was separated from the reaction solution and washed with ethanol, which was added to the ethanolic reaction solution, and the mixture was then filtered through a $0.45-\mu \mathrm{m}$ Millex LH filter. The filtrate was dried by speed-vac, and the residue was dissolved in $1 \mathrm{~mL}$ of distilled water. The total sugar concentration in the solution was analyzed by phenol-sulfuric assay [45]. Briefly, $1 \mathrm{~mL}$ of sample was mixed with $1 \mathrm{~mL}$ of $5 \%$ phenol and $5 \mathrm{~mL}$ of $98 \%$ sulfuric acid and incubated at room temperature for about $1 \mathrm{~h}$. Absorbance of the developed color was determined spectrophotometrically at $490 \mathrm{~nm}$. The amount of sugar content was deduced from the absorbance by comparing it with a standard curve $(0-100 \mu \mathrm{g} / \mathrm{mL})$ of galactose.

\section{Results and Discussion}

The investigation began with the homogeneous aerobic oxidation of benzyl alcohol in ethanol—an inexpensive, commercially available and relatively nontoxic and nonhazardous solvent-in the presence of various palladium salt catalysts (Table 1). In all of the reactions, only benzaldehyde was detected, without any benzoic acid or benzyl acetate leftovers, showing that the reaction is selective.

Table 1. Homogeneous and heterogeneous reactions in ethanol ${ }^{\mathrm{a}}$.

\begin{tabular}{|c|c|c|c|c|}
\hline Entry & Catalyst & Base $^{b}$ & $\operatorname{Pd}(\mathrm{OAc})_{2}$ Conversion $(\%)$ & $\mathrm{PdCl}_{2}$ Conversion $(\%)$ \\
\hline 1 & Homogeneous-No ligand & - & 50 & 0 \\
\hline 2 & Homogeneous-No ligand & + & 37 & 19 \\
\hline 3 & Homogeneous-TPP & - & 23 & 0 \\
\hline 4 & Homogeneous-TPP & + & 28 & 30 \\
\hline 5 & Homogeneous-TPPTS & - & 39 & 0 \\
\hline 6 & Homogeneous-TPPTS & + & 32 & 20 \\
\hline 7 & Heterogeneous & - & 20 & 0 \\
\hline 8 & Heterogeneous & + & 22 & 8 \\
\hline 9 & Heterogeneous $^{\mathrm{c}}$ & - & 12 & 0 \\
\hline 10 & Heterogeneous ${ }^{c}$ & + & 20 & 12 \\
\hline 11 & Heterogeneous ${ }^{d}$ & - & 21 & 14 \\
\hline 12 & Heterogeneous ${ }^{\mathrm{e}}$ & - & 22 & not tested \\
\hline 13 & Heterogeneous ${ }^{\mathrm{f}}$ & - & 40 & not tested \\
\hline
\end{tabular}

a Reaction conditions: $0.925 \mathrm{mmol}$ benzyl alcohol, $10 \mu \mathrm{mol}$ catalyst, $5 \mathrm{~mL}$ solvent, $60{ }^{\circ} \mathrm{C}, 1 \mathrm{~atm}$ air, $24 \mathrm{~h} .{ }^{\mathrm{b}}+$ refers to an addition of $0.092 \mu \mathrm{mol} \mathrm{Na} 2 \mathrm{CO}_{3}$; - without basis. ${ }^{\mathrm{c}} 3.8 \mathrm{~atm}$ air. ${ }^{\mathrm{d}}$ 1-Phenylethanol instead of benzyl alcohol. ${ }^{\mathrm{e}}$ 4-Methylbenzyl alcohol instead of benzyl alcohol. ${ }^{\mathrm{f}}$ 4-Methoxybenzyl alcohol instead of benzyl alcohol.

First, two commercially available palladium salts, palladium acetate and palladium chloride, were employed with or without the addition of a base: sodium carbonate (Table 1, entries 1 and 2). As can be seen from Table 1, the conversion rate with $\operatorname{Pd}(\mathrm{OAc})_{2}$ was found to be higher than with $\mathrm{PdCl}_{2}$ (Table 1, entry 1). Furthermore, while adding sodium carbonate to $\mathrm{Pd}(\mathrm{OAc})_{2}$ decreased the conversion rate, it increased the conversion rate when added to $\mathrm{PdCl}_{2}$, which was inactive without a base. Here the base assists both with the abstraction of the acidic alcohol of the benzyl alcohol, thus initiating the reaction, and with the dissociation of the anion from the catalyst.

Additionally, the addition of triphenyl phosphine (TPP) as a ligand, which can stabilize the catalyst and prevent reduction in the metal and formation of palladium black, resulted in lower conversion rates with $\mathrm{Pd}(\mathrm{OAc})_{2}$, but higher conversion rates with $\mathrm{PdCl}_{2}$ in the presence of a base (Table 1, entries 3 and 4). These results emphasize the difference between the two palladium salts, which can be attributed to their different solubilities in ethanol and the different natures of the chloride and acetate ions. Finally, as the heterogenization procedure involves the use of TPPTS as a ligand, the homogeneous reactions with both $\mathrm{Pd}(\mathrm{OAc})_{2}$ (TPPTS $)_{2}$ and $\mathrm{PdCl}_{2}$ (TPPTS $)_{2}$ were also tested (Table 1, entries 5 and 6 ). In the latter case, the conversion rate with $\mathrm{Pd}(\mathrm{OAc})_{2}(\mathrm{TPPTS})_{2}$ was lower than that with the 
free salt and higher than $\mathrm{Pd}(\mathrm{OAc})_{2}(\mathrm{TPP})_{2}$, but still higher than the conversion rate with $\mathrm{PdCl}_{2}$ (TPPTS $)_{2}$, which was similar to that when using salt alone.

Based on our previous work, iota (i) carrageenan was selected as the support for the heterogeneous system [38-44]. With this support, the reaction with $i-\mathrm{Pd}(\mathrm{OAc})_{2}(\mathrm{TPPTS})_{2}$ was superior to that with $i-\mathrm{PdCl}_{2}$ (TPPTS) 2 (Table 1, entries 7 and 8). Increasing the air pressure from $1 \mathrm{~atm}$ to $3.8 \mathrm{~atm}$ slightly decreased the conversion rates, perhaps because of the high concentration of nitrogen that was adsorbed on the palladium surface (Table 1, entries 9 and 10). Lastly, various benzylic alcohols were tested and also successfully oxidized using the new heterogeneous catalysts. In those tests, the addition of an electron donating group, such as methoxy, was found to significantly increase the conversion rate (Table 1, entries 11-13). However, aliphatic alcohols, which are less prone to aerobic oxidation, showed only negligible conversion rates. Next, to better evaluate the applicability of the new heterogeneous system, we tested the ability of both $i$-based catalysts to be recycled and the ability of the system to function for multiple runs (Table 2).

Table 2. Catalyst recycling in ethanol ${ }^{\mathrm{a}}$.

\begin{tabular}{ccc}
\hline Cycle & $\begin{array}{c}\boldsymbol{i} \text {-Pd(OAc) }{ }_{\mathbf{2}}(\mathrm{TPPTS})_{2} \\
\text { Conversion (\%) }\end{array}$ & $\begin{array}{c}\boldsymbol{i} \text {-PdCl }_{\mathbf{2}} \mathbf{T P P T S}_{\mathbf{2}} \\
\text { Conversion (\%) }^{\mathbf{b}}\end{array}$ \\
\hline 1 & 20 & 8 \\
2 & 29 & 11 \\
3 & 35 & 15 \\
\hline
\end{tabular}

a Reaction conditions: $0.925 \mathrm{mmol}$ benzyl alcohol, $10 \mu \mathrm{mol}$ catalyst, $5 \mathrm{~mL}$ solvent, $60^{\circ} \mathrm{C}, 1 \mathrm{~atm}$ air, $24 \mathrm{~h} .{ }^{\mathrm{b}}$ Addition of $0.092 \mu \mathrm{mol} \mathrm{Na} \mathrm{CO}_{3}$.

As illustrated in Table 2, in the new heterogeneous systems the catalysts could be easily separated from the reaction mixture and recycled, while running the reaction again with the filtered reaction mixture after catalyst removal did not result in an increase in the conversion, thus hinting that the catalyst had not leached into the solution. Furthermore, ICP-OES analysis did not reveal any leftover palladium in the solution, indicating that there was no palladium leaching. Moreover, and surprisingly, the reaction cycles run after the first and second times the catalysts were recycled (Table 2, entries 2 and 3) yielded higher conversion rates than the initial reaction cycle. To test the stability of the heterogeneous catalyst under the reaction conditions, the sugar content in the reaction mixture after each cycle was measured by using the colorimetric phenol-sulphuric method. The sugar content in the reaction solution at the end of each cycle was negligible compared to the amount of polysaccharide used to prepare the catalyst (less than $50 \mu \mathrm{g}$ sugar compared to $0.03 \mathrm{~g}$ polysaccharide initially used). This observation indicates that the heterogeneous catalyst almost did not degrade and/or was dissolved in the reaction solution, even though the reaction conditions comprised mixing at under $60^{\circ} \mathrm{C}$ for $72 \mathrm{~h}$.

In addition, the color of the catalyst grew darker from cycle to cycle. We suggest that this may be attributed to the formation of palladium nanoparticles while heating the catalyst under reaction conditions, as was previously reported under similar reaction conditions in a Suzuki-cross coupling in ethanol [35].

The next step was to rigorously evaluate the state and form of the palladium (and its distribution within the fresh heterogeneous catalyst) and the catalyst after $24 \mathrm{~h}$ of reaction. Both samples were analyzed by TEM (Figure 2).

As expected, the TEM image of $i-\mathrm{Pd}(\mathrm{OAc})_{2}$ (TPPTS $)_{2}$ fresh catalyst (Figure 2A) showed that nanoparticles had already been created during the lyophilization of the polysaccharidecatalyst mixture, which is in agreement with previously published findings [38,39]. However, employing the catalysts in the reaction and heating it for $24 \mathrm{~h}$ at $60^{\circ} \mathrm{C}$ resulted in the formation of much larger nanoparticles than previously reported, as illustrated in Figure 2B. This implies that the reaction conditions promoted reduction in the palladium and nanoparticle aggregation [39]. 
A-

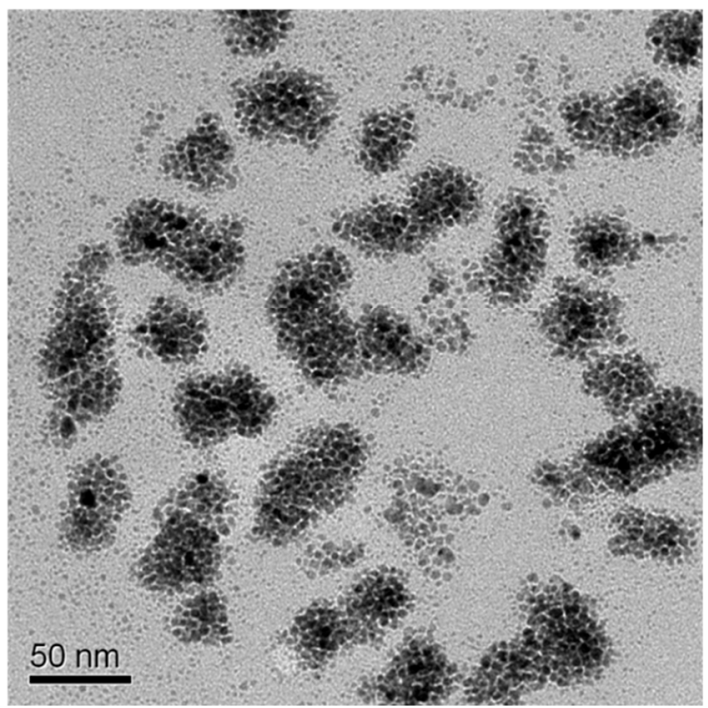

B-

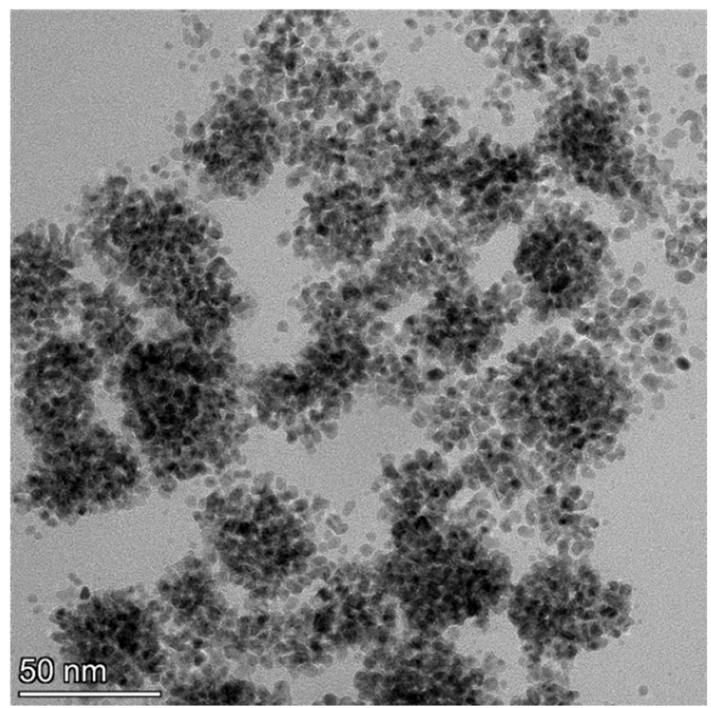

Figure 2. TEM micrographs of $i$-Pd(OAc) $)_{2}(\mathrm{TPPTS})_{2}$ : (A) Before reaction; (B) After $24 \mathrm{~h}$ of reaction.

Nanoparticles of palladium have been intensively studied in a wide range of catalytic applications, including C-C coupling reactions (e.g., Suzuki, Heck, Sonogashira, Negishi, Stille, Kumada and Hiyama), hydrogenation and electrochemical reactions in fuel cells $[33,35]$. There are also several reports showing the successful employment of palladium nanoparticles in oxidation reactions. For example, palladium nanocatalysts with carbon nanomaterial support have been successfully applied in a glucose oxidation reaction [46]. Additionally, a biphasic aerobic oxidation of alcohols was performed by using palladium nanoparticles in a polyethylene glycol matrix as the catalyst and supercritical carbon dioxide as the substrate and product phase [29]. In contrast to our findings, however, it is well known that the aggregation of palladium nanoparticles, which results in a reduction in the surface area-to volume ratio, usually renders palladium nanoparticles less active and selective [33]. It was therefore suggested that other factors are responsible for the reaction enhancement effect, such as changes in the palladium oxidation state, palladium distribution on the surface, palladium nanoparticle morphologies, rate of nanoparticle formation, changes in the support structure, mass transfer limitations, etc.

Analysis by XPS was used to better understand the changes in the elemental distribution on the heterogeneous catalyst and to determine the oxidation state of the palladium on the surface before and after the reaction. The analysis showed that the palladium atomic concentration on the surface of both preparations was similar, $0.5 \%$, and in agreement with the amount that was used to form the heterogeneous catalyst. Moreover, the elemental identification and quantification of $i-\mathrm{Pd}(\mathrm{OAc})_{2}(\mathrm{TPPTS})_{2}$ before and after the reaction was also similar in both preparations, as shown in Table 3.

Curve-fitting of the Pd3d spectra of the two preparations (Figure 3) shows that both consist of a doublet ( $\mathrm{Pd} 3 \mathrm{~d} 5 / 2$ and $\mathrm{Pd} 3 \mathrm{~d} 3 / 2$ ) due to spin-orbit splitting, and each component of the doublet involves two peaks, assigned to $\mathrm{Pd}(0)$ and $\mathrm{Pd}(\mathrm{II})$. However, the two samples exhibited different ratios between the two oxidation states.

In the spectrum results for the fresh heterogeneous catalyst, the area percentage peaks of the $\mathrm{Pd}(0)$ and $\mathrm{Pd}(\mathrm{II})$ correspond to $24 \%$ and $76 \%$, respectively (Figure $3 \mathrm{~A}$ ). For the post-reaction heterogeneous catalyst, the area percentage peaks of the $\mathrm{Pd}(0)$ and $\mathrm{Pd}(\mathrm{II})$ correspond to $70 \%$ and $30 \%$, respectively (Figure 3B). This shows that $46 \%$ of the $\operatorname{Pd}(\mathrm{II})$, derived from $\mathrm{Pd}(\mathrm{OAc})_{2}$, was reduced to metallic form during $24 \mathrm{~h}$ of reaction with binding energies of $\mathrm{Pd}(0) 3 \mathrm{~d}(\mathrm{~d} 5335.6 \mathrm{eV}$; d3 $341.6 \mathrm{eV}$ ) (Figure 3). Thus, it seems that the enhancement in catalytic activity after recycling of the xerogel can be attributed to the increase in the $\operatorname{Pd}(0)$ form. 
Table 3. Elemental identification and quantification of $i$-Pd(OAc $)_{2}(\mathrm{TPPTS})_{2}$ before and after reaction, determined by XPS.

\begin{tabular}{ccc}
\hline Element & $\begin{array}{c}\text { Atomic } \% \\
\text { before Reaction }\end{array}$ & $\begin{array}{c}\text { Atomic } \% \\
\text { before Reaction }\end{array}$ \\
\hline C1s & 56.76 & 55.99 \\
O1s & 31.91 & 31.26 \\
N1s & 0.58 & 0.51 \\
Pd3d & 0.50 & 0.49 \\
Na1s & 2.07 & 2.75 \\
Ca2p & 1.09 & 1.32 \\
S2p & 6.43 & 6.98 \\
K2p & 0.68 & 0.69 \\
\hline
\end{tabular}

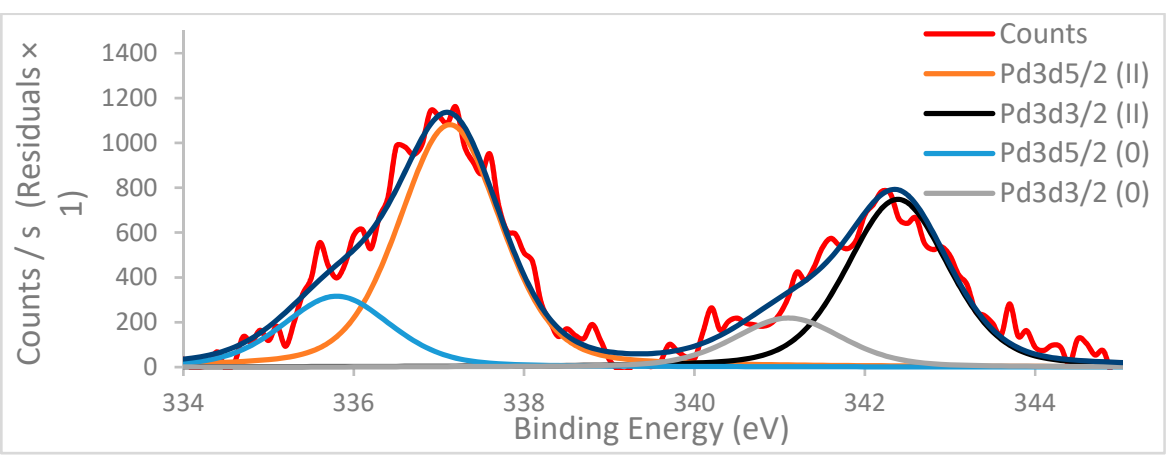

(A)

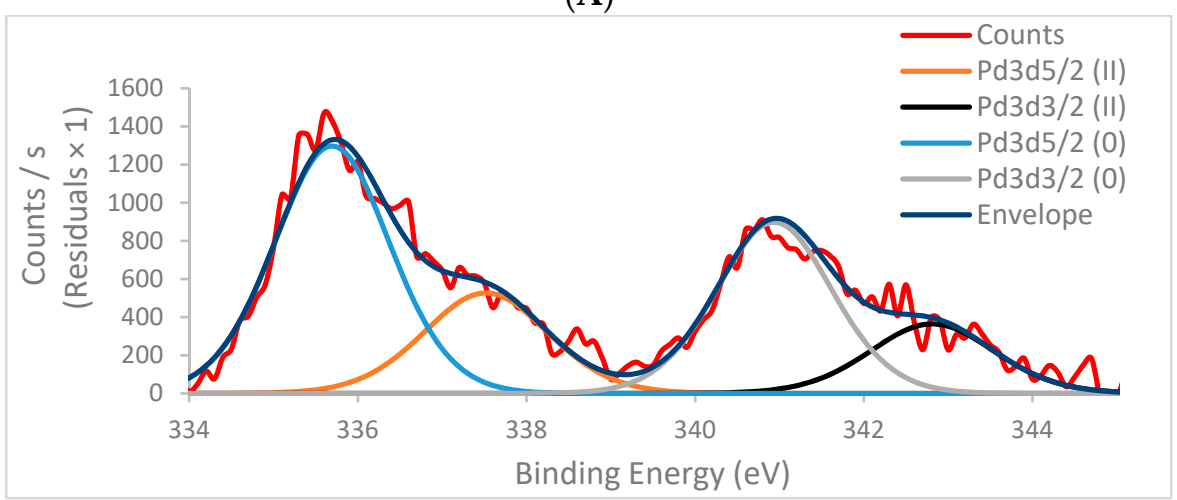

(B)

Figure 3. XPS spectra of $i-\mathrm{Pd}(\mathrm{OAc})_{2}(\mathrm{TPPTS})_{2}$ in the Pd3d region (A) Before reaction, (B) After $24 \mathrm{~h}$ of reaction.

The elemental analysis of $i-\mathrm{Pd}(\mathrm{OAc})_{2}(\mathrm{TPPTS})_{2}$ before and after the reaction was also investigated via SEM-EDS (Figure 4). Representative EDS spectra of various samples revealed that the palladium atomic concentration in both preparations was $0.5 \%$, which is in agreement with the amount used to form the xerogel catalyst and the amount shown in the XPS analysis, indicating that the palladium was probably uniformly dispersed in the xerogel. Similarly, the molar elemental ratio of P:Pd in the heterogeneous catalyst was found to be 3:1, as in the homogeneous catalyst (data not shown). What this suggests is that the complex, $i-\mathrm{Pd}(\mathrm{OAc})_{2}(\mathrm{TPPTS})_{2}$, has kept its elemental composition despite the reaction conditions. However, the images of both samples obtained using SEM indicate that the structures are different. While the $i-\mathrm{Pd}(\mathrm{OAc})_{2}(\mathrm{TPPTS})_{2}$ xerogel before the reaction is characterized by a porous sphere or structure with hollows (Figure 4A), the xerogel that appears during the $24 \mathrm{~h}$ of reaction is characterized by ordered vertical porous tubes (Figure 4B). Indeed, the structural differences can be observed by physical contact: the xerogel becomes more rigid after the reaction. Therefore, it seems that structural changes 
also play a major factor that can pose a mass transfer limitation that can affect reaction performances between successive cycles.

A

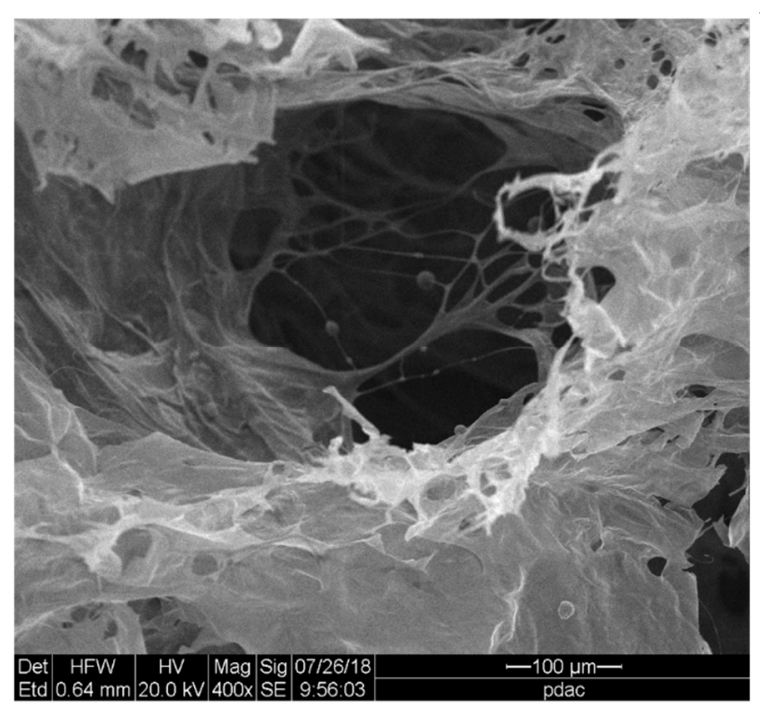

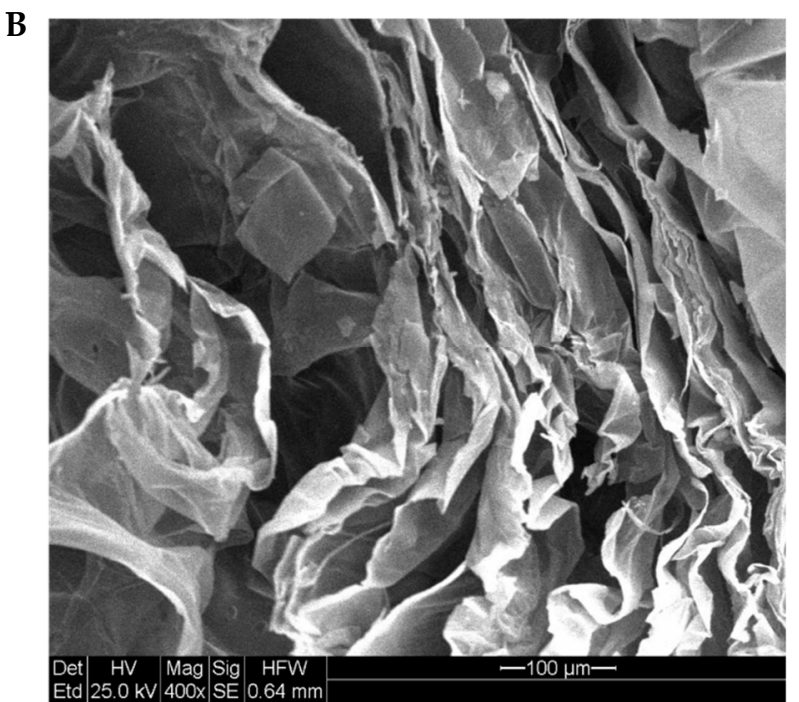

Figure 4. Secondary scanning electron microscopy (SEM) imaging of $i$-Pd(OAc) $)_{2}(\mathrm{TPPTS})_{2}:(\mathbf{A})$ Before reaction; $(\mathbf{B})$ After $24 \mathrm{~h}$ of reaction.

\section{Conclusions}

$i-\mathrm{Pd}(\mathrm{OAc})_{2}(\mathrm{TPPTS})_{2}$ and $i-\mathrm{PdCl}_{2}(\mathrm{TPPTS})_{2}$, prepared using a very simple and straightforward method, were successfully employed in the aerobic oxidation of benzylic alcohols. After $24 \mathrm{~h}$ pf reaction, the conversion rate of benzyl alcohol with $i-\mathrm{Pd}(\mathrm{OAc})_{2}(\mathrm{TPPTS})_{2}(22 \%)$ was higher than that with $i-\mathrm{PdCl}_{2}$ (TPPTS $)_{2}(8 \%)$ and close to that of the parent homogeneous complex (32\%). In this novel method, the metal did not leach into the reaction mixture and the catalyst was successfully recycled twice, exhibiting increases in activity in the reactions after the first and second times it was recycled from an initial conversion rate of $22 \%$ to $29 \%$ in the first recycle and $35 \%$ in the second. Notably, both the catalyst matrix and the solvent used in this approach are environmentally preferable, thus making this approach of general interest for the pursuit of viable "green" nanoparticle catalysis systems. Characterization of the lyophilized $i-\operatorname{Pd}(\mathrm{OAc})_{2}(\text { TPPTS })_{2}$ system via TEM, XPS and SEM-EDS analyses before and after the reaction in ethanol shows that the palladium was successfully dispersed and embedded in the xerogel and that palladium nanoparticles formed during the reaction and led to higher conversion rates. In addition, the structure of the $i-\mathrm{Pd}(\mathrm{OAc})_{2}(\mathrm{TPPTS})_{2}$ was altered in the course of the reaction.

Author Contributions: O.L.-O. and A.W. conceived and designed the experiments, analyzed the data and wrote the paper. E.S. performed the experiments. All authors have read and agreed to the published version of the manuscript.

Funding: This research received no external funding.

Institutional Review Board Statement: Not applicable.

Informed Consent Statement: Not applicable.

Data Availability Statement: The data presented in this study are available on request from the corresponding author.

Conflicts of Interest: The authors declare no conflict of interest.

\section{References}

1. Bäckvall, J.E. Modern Oxidation Methods; John Wiley \& Sons: New York, NY, USA, 2011; p. 481. 
2. Kopylovich, M.N.; Ribeiro, A.P.; Alegria, E.C.; Martins, N.M.; Martins, L.M.; Pombeiro, A.J. Catalytic oxidation of alcohols: Recent advances. In Advances in Organometallic Chemistry; Perez, P., Ed.; Academic Press: Cambridge, MA, USA, 2015 ; pp. 91-174.

3. Iwabuchi, Y. Green Oxidation in Organic Synthesis; John Wiley \& Sons: New York, NY, USA, 2019; pp. 35-78.

4. Tojo, G.; Fernandez, M.I. Oxidation of Alcohols to Aldehydes and Ketones: A Guide to Current Common Practice; Springer Science \& Business Media: New York, NY, USA, 2006; p. 376.

5. Waters, W.A. Mechanisms of oxidation by compounds of chromium and manganese. Q. Rev. Chem. Soc. 1958, 12, 277-300. [CrossRef]

6. Sheldon, R.A. Recent advances in green catalytic oxidations of alcohols in aqueous media. Catal. Today 2015, 247, 4-13. [CrossRef]

7. Yu, Y.; Lu, B.; Wang, X.; Zhao, J.; Wang, X.; Cai, Q. Highly selective oxidation of benzyl alcohol to benzaldehyde with hydrogen peroxide by biphasic catalysis. Chem. Eng. J. 2010, 162, 738-742. [CrossRef]

8. Ueno, M.; Ohmura, S.D.; Wada, M.; Miyoshi, N. Aerobic oxidation of alcohols using bismuth bromide as a catalyst. Tetrahedron Lett. 2019, 60, 570-573. [CrossRef]

9. Landaeta, V.R.; Rodríguez-Lugo, R.E. Catalytic Aerobic Oxidations: Aerobic Oxidation Reactions in the Fine Chemicals and Pharmaceutical Industries. In Catalytic Aerobic Oxidations; Mejía, E., Ed.; Royal Society of Chemistry: Cambridge, UK, 2020; pp. 252-290.

10. Silva, T.F.; Martins, L.M. Recent Advances in Copper Catalyzed Alcohol Oxidation in Homogeneous Medium. Molecules 2020, 25, 748. [CrossRef] [PubMed]

11. Guðmundsson, A.; Schlipköter, K.E.; Bäckvall, J.E. Iron (II)-Catalyzed Biomimetic Aerobic Oxidation of Alcohols. Angew. Chem. Int. 2020, 132, 5441-5444. [CrossRef]

12. Parmeggiani, C.; Cardona, F. Transition metal based catalysts in the aerobic oxidation of alcohols. Green Chem. 2012, 14, 47-564. [CrossRef]

13. Cardona, F.; Parmeggiani, C. Overview: Representative experimental procedures, comparative tables and conclusions. In Transition Metal Catalysis in Aerobic Alcohol Oxidation; Cardona, F., Parmeggiani, C., Eds.; Royal Society of Chemistry: Canbridge, UK, 2014; pp. 256-283.

14. Stahl, S.S. Palladium oxidase catalysis: Selective oxidation of organic chemicals by direct dioxygen-coupled turnover. Angew. Chem. Int. 2004, 43, 3400-3420. [CrossRef]

15. Karimi, B.; Zamani, A. Recent advances in the homogeneous palladium-catalyzed aerobic oxidation of alcohols. J. Iran. Chem. Soc. 2008, 5, S1-S20. [CrossRef]

16. Vino, C.P.; Wilson, K.; Lee, A.F. Recent advances in the heterogeneously catalysed aerobic selective oxidation of alcohols. J. Chem. Technol. Biotechnol. 2011, 86, 161-171. [CrossRef]

17. Parmeggiani, C.; Matassini, C.; Cardona, F. A step forward towards sustainable aerobic alcohol oxidation: New and revised catalysts based on transition metals on solid supports. Green Chem. 2017, 19, 2030-2050. [CrossRef]

18. Ali, M.; Rahman, M.; Sarkar, S.M.; Hamid, S.B. Heterogeneous metal catalysts for oxidation reactions. J. Nanomater. 2014, 1, 192038. [CrossRef]

19. Ji, H.B.; Ebitani, K.; Mizugaki, T.; Kaneda, K. Environmentally friendly alcohol oxidation using heterogeneous catalyst in the presence of air at room temperature. Catal. Commun. 2002, 3, 511-517. [CrossRef]

20. Sun, H.Y.; Hua, Q.; Guo, F.F.; Wang, Z.Y.; Huang, W.X. Selective aerobic oxidation of alcohols by using manganese oxide nanoparticles as an efficient heterogeneous catalyst. Adv. Synth Catal. 2012, 354, 569-573. [CrossRef]

21. Zhou, W.; Tao, Q.; Pan, J.; Liu, J.; Qian, J.; He, M.; Chen, Q. Effect of basicity on the catalytic properties of Ni-containing hydrotalcites in the aerobic oxidation of alcohol. J. Mol. Catal. A Chem. 2016, 425, 255-265. [CrossRef]

22. Kazuya, Y.; Mori, K.; Mizugaki, T.; Ebitani, K.; Kaneda, K. Creation of a monomeric Ru species on the surface of hydroxyapatite as an efficient heterogeneous catalyst for aerobic alcohol oxidation. J. ACS 2000, 122, 7144-7145.

23. Zhu, J.; Kailasam, K.; Fischer, A.; Thomas, A. Supported cobalt oxide nanoparticles as catalyst for aerobic oxidation of alcohols in liquid phase. ACS Catal. 2011, 1, 342-347. [CrossRef]

24. Miyamura, H.; Matsubara, R.; Miyazaki, Y.; Kobayashi, S. Aerobic oxidation of alcohols at room temperature and atmospheric conditions catalyzed by reusable gold nanoclusters stabilized by the benzene rings of polystyrene derivatives. Angev. Chem. Int. 2007, 46, 4151-4154. [CrossRef]

25. Karimi, B.; Zamani, A.; Abedi, S.; Clark, J.H. Aerobic oxidation of alcohols using various types of immobilized palladium catalyst: The synergistic role of functionalized ligands, morphology of support, and solvent in generating and stabilizing nanoparticles. Green Chem. 2009, 11, 109-119. [CrossRef]

26. Wu, G.; Wang, X.; Guan, N.; Li, L. Palladium on graphene as efficient catalyst for solvent-free aerobic oxidation of aromatic alcohols: Role of graphene support. Appl. Catal. B Environ. 2013, 136, 177-185. [CrossRef]

27. Kwon, M.S.; Kim, N.; Park, C.M.; Lee, J.S.; Kang, K.Y.; Park, J. Palladium nanoparticles entrapped in aluminum hydroxide: Dual catalyst for alkene hydrogenation and aerobic alcohol oxidation. Org. Lett. 2005, 7, 1077-1079. [CrossRef]

28. Chen, Y.; Zheng, H.; Guo, Z.; Zhou, C.; Wang, C.; Borgna, A.; Yang, Y. Pd catalysts supported on MnCeOx mixed oxides and their catalytic application in solvent-free aerobic oxidation of benzyl alcohol: Support composition and structure sensitivity. J. Catal. 2011, 283, 34-44. [CrossRef] 
29. Hou, Z.; Theyssen, N.; Brinkmann, A.; Leitner, W. Biphasic Aerobic Oxidation of Alcohols Catalyzed by Poly (ethylene glycol)Stabilized Palladium Nanoparticles in Supercritical Carbon Dioxide. Angew. Chem. Int. 2005, 44, 1346-1349. [CrossRef] [PubMed]

30. Verma, S.; Tripathi, D.; Gupta, P.; Singh, R.; Bahuguna, G.M.; Chauhan, R.K.; Saran, S.; Jain, S.L. Highly dispersed palladium nanoparticles grafted onto nanocrystalline starch for the oxidation of alcohols using molecular oxygen as an oxidant. Dalton Trans. 2013, 42, 11522-11527. [CrossRef] [PubMed]

31. Johnston, E.V.; Verho, O.; Kärkäs, M.D.; Shakeri, M.; Tai, C.W.; Palmgren, P.; Eriksson, K.; Oscarsson, S.; Bäckvall, J.E. Highly dispersed palladium nanoparticles on mesocellular foam: An efficient and recyclable heterogeneous catalyst for alcohol oxidation. Chem. Euro J. 2012, 18, 12202-12206. [CrossRef]

32. Tang, L.; Guo, X.; Li, Y.; Zhang, S.; Zha, Z.; Wang, Z. Pt, Pd and Au nanoparticles supported on a DNA-MMT hybrid: Efficient catalysts for highly selective oxidation of primary alcohols to aldehydes, acids and esters. Chem. Commun. 2013, 49, 5213-5215. [CrossRef]

33. Shakil Hussain, S.M.; Kamal, M.S.; Hossain, M.K. Recent developments in nanostructured palladium and other metal catalysts for organic transformation. J. Nanomater. 2019, 20. [CrossRef]

34. Wolfson, A.; Levy-Ontman, O. Recent Developments in the Immobilization of Palladium Complexes on Renewable Polysaccharides for Suzuki-Miyaura Cross-Coupling of Halobenzenes and Phenylboronic Acids. Catalysts 2020, 10, 136. [CrossRef]

35. Wolfson, A.; Levy-Ontman, O. Development and application of palladium nanoparticles on renewable polysaccharides as catalysts for the Suzuki cross-coupling of halobenzenes and phenylboronic acids. Mol. Catal. 2020, 493, 111048. [CrossRef]

36. Kumbhar, A.; Salunkhe, R. Recent advances in biopolymer supported palladium in organic synthesis. Curr. Org. Chem. 2015, 19, 2075-2121. [CrossRef]

37. Nasrollahzadeh, M. Green synthesis and catalytic properties of palladium nanoparticles for the direct reductive amination of aldehydes and hydrogenation of unsaturated ketones. New J. Chem. 2014, 38, 5544-5550. [CrossRef]

38. Levy-Ontman, O.; Biton, S.; Shlomov, B.; Wolfson, A. Renewable polysaccharides as supports for palladium phosphine catalysts. Polymers 2018, 1, 659. [CrossRef]

39. Wolfson, A.; Biton, S.; Levy-Ontman, O. Study of Pd-based catalysts within red algae-derived polysaccharide supports in a Suzuki cross-coupling reaction. RSC Adv. 2018, 8, 37939-37948. [CrossRef]

40. Levy-Ontman, O.; Blum, D.; Golden, R.; Pierschel, E.; Leviev, S.; Wolfson, A. Palladium Based-Polysaccharide Hydrogels as Catalysts in the Suzuki Cross-Coupling Reaction. J. Inorg. Organomet. Polym. Mater. 2020, 30, 622-636. [CrossRef]

41. Leviev, S.; Wolfson, A.; Levy-Ontman, O. $\mathrm{RhCl(TPPTS})_{3}$ supported on iota-carrageenan as recyclable catalysts for Suzuki cross-coupling. J. Appl. Polym. Sci. 2019, 136, 48200. [CrossRef]

42. Leviev, S.; Wolfson, A.; Levy-Ontman, O. Novel iota carrageenan-based $\mathrm{RhCl}_{3}$ as an efficient and recyclable catalyst in Suzuki cross coupling. Mol. Catal. 2020, 486, 110841. [CrossRef]

43. Wolfson, A.; Pierschel, E.; Orzehovsky, T.; Nirenberg, S.; Levy-Ontman, O. Heterogeneous iota carrageenan-based palladium catalysts for organic synthesis. Org. Comm. 2019, 12, 149-159. [CrossRef]

44. Levy-Ontman, O.; Tabibian, B.; Shaklein, S.; Tzur, E.; Wolfson, A. Acceleration of transfer-hydrogenation of cyclohexene with palladium catalysts in the presence of polysaccharides. Org. Comm. 2020, 13, 138-145. [CrossRef]

45. Dubois, M.; Gilles, K.A.; Hamilton, J.K.; Rebers, P.T.; Smith, F. Colorimetric method for determination of sugars and related substances. Anal. Chem 1956, 28, 350-356. [CrossRef]

46. Chen, C.C.; Lin, C.L.; Chen, L.C. Functionalized carbon nanomaterial supported palladium nano-catalysts for electrocatalytic glucose oxidation reaction. Electrochim. Acta 2015, 152, 408-416. [CrossRef] 